\title{
COEXISTENT TOPHACEOUS GOUT AND RHEUMATOID ARTHRITIS: A CASE REPORT
}

Preeti Singh Dhoat ${ }^{1}$, Ashok Khurana², Jivesh Mittal ${ }^{3}$, Amandeep Kaur Sandhư ${ }^{4}$, Jivteshpreet Singh ${ }^{5}$

\section{HOW TO CITE THIS ARTICLE:}

Preeti Singh Dhoat, Ashok Khurana, Jivesh Mittal, Amandeep Kaur Sandhu, Jivteshpreet Singh. "Coexistent Tophaceous Gout and Rheumatoid Arthritis. A Case Report". Journal of Evolution of Medical and Dental Sciences 2014; Vol. 3, Issue 14, April 07; Page: 3685-3688, DOI: 10.14260/jemds/2014/2344

ABSTRACT: We report a rare case of a 50 year old Indian male patient with concomitant tophaceous gout and rheumatoid arthritis (RA) who presented with intradermal tophaceous deposits at some very rare sites. The presence of RA was confirmed by the presence of positive anti-CCP levels as compared to some other rare case reports where nonspecific rheumatoid factor substantiated the presence of RA. The presentation, diagnostic work up and management is discussed and the current literature pertaining to this interesting case is reviewed.

KEYWORDS: Gout, rheumatoid arthritis.

INTRODUCTION: The negative correlation between gout and rheumatoid arthritis (RA) is widely accepted, but the reasons are unclear. ${ }^{1}$ These conditions are not typically identified concomitantly and can be hard to distinguish from one another. However, as separate disease entities, they are relatively commonly observed in the general population. Possible reasons for the mutual exclusion between these diseases include an anti-inflammatory or immuno-suppressive effect of hyperuricemia ${ }^{2-5}$ and inhibition of crystal deposition by possible connective tissue alterations in RA. ${ }^{6}$

Tophaceous gout is an uncommon condition with tophi being reported commonly at the great toe, feet, hand joints and olecranon. However tophi of the helix of the ear, though classic is a very rare occurrence.

The purpose of presenting this case of gout and rheumatoid arthritis is its rarity in combination and the clinical features of tophaceous deposits at the helix and especially at the back where it has rarely been reported. Although a few concurrent cases of gout and Rheumatoid factor positive RA have been described, the present report showed intradermal tophaceous gout and antiCCP positive RA.

CASE REPORT: A 50 years/M named Butta Singh, was admitted to our hospital with complaints of multiple swellings on both hands, feet and back.

On history, he had joint pains for the last 12 years, beginning with the involvement of the metatarsophalangeal joint of the left feet. He had frequent attacks of joint pain with exacerbations and with varying periods of remissions in which he had no residual symptoms until the next episode. However over the next 5 years or so, gradually most of the other joints were involved as well including joints of the hand, ankle, knees, shoulders and elbow symmetrically.

All of this time, patient remained on pain killers and some indigenous medications without much relief. Four years prior to his admission with us, patient was investigated and was diagnosed with rheumatoid arthritis. His anti-CCP was positive then with an ESR of $70 \mathrm{~mm} / \mathrm{h}$. Patient was put on Tab methotrexate $7.5 \mathrm{mg}$ once a week. 
Patients past medical history was significant for hypertension, diabetes mellitus and chronic alcoholism.

Six months prior to his admission with us, he developed swellings at multiple sites. On detailed examination, the swellings were present at the metatarsal joints of both feet, Achilles tendon bilaterally, at the metacarpophalangeal joints of both hands, lower back bilaterally and helix of the ear. The swellings were multiple, firm, nodular, non-tender, immobile with no signs of inflammation. The deformities of RA were present in the form of ulnar deviation of the hand, Boutonniere's deformity and $\mathrm{Z}$ deformity.

Lab investigation revealed hemoglobin of $8.0 \mathrm{~g} / \mathrm{dl}$, ESR $36 \mathrm{~mm} / \mathrm{h}$ and white blood cell count of $9500 / \mathrm{mm}^{3}$ with normal differential count. His blood urea was $112 \mathrm{mg} / \mathrm{dl}$ and serum creatinine was $4.2 \mathrm{mg} / \mathrm{dl}$. The serum uric acid was $11.2 \mathrm{mg} / \mathrm{dl}$. The 24 hour urinary uric acid was $780 \mathrm{mg} / \mathrm{dl}$. His anti-CCP was raised, being $6.7 \mathrm{U} / \mathrm{ml}$. RA factor was negative.

Fine needle aspiration cytology of the swelling at the feet and back was done and it showed presence of monosodium urate crystals suggestive of gout.

X-ray of both feet showed destruction with periosteal reaction and soft tissue swelling at the metatarsal head and proximal phalanx of great toe with erosion of head of metatarsal and proximal phalanx of little toe.

Because of the high serum creatinine level, methotrexate was omitted and the patient was put on febuxostat $80 \mathrm{mg}$ once daily.

DISCUSSION: Our patient is an example of one of the few convincing cases of coexistent tophaceous gout and rheumatoid arthritis. Symmetric arthritis with positive anti-CCP supported the diagnosis of RA. The radiological findings of soft tissue swelling, symmetric joint space loss, and subchondral erosions most frequently in the wrists and hands (MCP's and PIP's) and the feet (MTP's) though consistent with RA, are not typically present with chronic tophaceous gout.

The deformities in the form of ulnar deviation of the hand, boutonniere's deformity and $\mathrm{Z}$ deformity further substantiated the presence of rheumatoid arthritis beyond doubt.

The markedly increased serum uric acid level and the presence of urate crystals in the intradermal swellings at the feet and back confirmed the presence of tophaceous gout. gout, which is caused by the overproduction of uric acid, is a common medical diagnosis that can have a presentation similar to rheumatoid arthritis (RA).7,8

Most of the few case reports of concomitant gout and RA earlier have focused on the Rheumatoid factor (RF) for the diagnosis of rheumatoid arthritis with concomitant gout. The presence of RF is not restricted to patients with RA, but that it can also be detected in subsets of patients suffering from other diseases and even in a percentage of healthy (especially elderly) individuals. ${ }^{9}$ The resulting lack of specificity for RA can lead to confusion and unwanted treatment. Anti-CCP combines RF-like sensitivity with almost absolute specificity for RA.9, 10, 11

The anti-CCP test also enables clinicians to effectively distinguish RA patients from other arthritic diseases in cases where the RF is not always discriminative. Anti-CCP antibodies are a highly specific marker for RA in several diverse patient groups.

This specificity extends to patients with early disease, in whom a timely diagnosis is most needed. The low sensitivity of the test (40-50\% in most published cohorts) indicates that a negative 
anti-CCP antibody test does not exclude disease, but its high specificity means that a positive result markedly increases the probability that the patient will have RA.

CONCLUSION: Tophaceous gout is a rare clinical manifestation that has been observed in patients with history of chronic gout. Although chronic gout and RA are common clinical entities, they seldom coexist. ${ }^{8,12-14}$ In understanding the specific-yet sometimes similar presentations of both conditions, physicians can better diagnose and treat their patients.

\section{REFERENCES:}

1. Wallace D J, Klinenberg J R, Morhaim D, Berlanstein B, Biren P C, Callis G. Coexistent gout and rheumatoid arthritis: Case report and literature review. Arthritis Rheum 1979; 22: 81-6.

2. Lussier A, DeMedicis R. Inhibition of adjuvant-induced arthritis in the Hyperuricaemic rat. Agents Actions 1978; 8:536-42.

3. Schwartz M L, Malawista S E. Dosage-dependent inhibition of phagocytosis by human leukocytes exposed to urate in solution (abstract). Arthritis Rheum 1975; 18: 424.

4. Turner R A, Pisko E J, Agudelo C A, Counts G B, Foster S L. Uric acid effects on in vitro models of rheumatoid inflammatory and autoimmune processes. Ann Rheum Dis 1983; 42: 338-42.

5. Ames B N, Cathcart R, Schwiers E, Hochstein P. Uric acid provides an antioxidant defense in humans against oxidant- and radical-caused aging and cancer: a hypothesis. Proc Natl Acad Sci USA 1981; 78: 6858-62.

6. Schumacher H R. Pathogenesis of crystal-induced synovitis. Clin Rheum Dis 1977; 3: 105-31.

7. Terkeltaub RA. Gout. N Engl J Med. 2003; 349:1647-1655.

8. Zonana-Nacach A, Alarcón GS, Daniel WW. Rheumatoid arthritis preceding the onset of polyarticular tophaceous gout [letter]. Ann Rheum Dis.1996; 55:489-490.

9. Van Venrooij WJ, Hazes JM, Visser H. Anticitrullinated protein/peptide antibody and its role in the diagnosis and prognosis of early rheumatoid arthritis. Neth J Med2002; 60:383-8.

10. Pinheiro GC, Scheinberg MA, Aparecida da Silva M, Maciel S. Anti-cyclic citrullinated peptide antibodies in advanced rheumatoid arthritis. Ann Intern Med2003; 139:234-5.

11. Vasishta A. Diagnosing early-onset rheumatoid arthritis: the role of anti-CCP antibodies. Am Clin Lab 2002; 21:34-6.

12. Gordon TP, Ahern MJ, Reid C, Roberts-Thomson PJ. Studies on the interaction of rheumatoid factor with monosodium urate crystals and case report of coexistent tophaceous gout and rheumatoid arthritis. Ann Rheum Dis.1985; 44:384-389.

13. Raman D, Abdalla AM, Newton DRL, Haslock I. Coexistent rheumatoid arthritis and tophaceous gout: a case report. Ann Rheum Dis. 1981; 40:427-429.

14. Khosla P, Gogia A, Agarwal PK, Pahuja A, Jain S, Saxena KK. Concomitant gout and rheumatoid arthritis-a case report. Indian J Med Sci. 2004; 58:349-352. 


\section{CASE REPORT}

\section{AUTHORS:}

1. Preeti Singh Dhoat

2. Ashok Khurana

3. Jivesh Mittal

4. Amandeep Kaur Sandhu

5. Jivteshpreet Singh

\section{PARTICULARS OF CONTRIBUTORS:}

1. Assistant Professor, Department of General Medicine, Sri Guru Ram Das Institute of Medical Sciences and Research, Amritsar.

2. Professor, Department of General Medicine, Sri Guru Ram Das Institute of Medical Sciences and Research, Amritsar.

3. Post Graduate, Department of General Medicine, Sri Guru Ram Das Institute of Medical Sciences and Research, Amritsar.
4. Post Graduate, Department of General Medicine, Sri Guru Ram Das Institute of Medical Sciences and Research, Amritsar.

5. Post Graduate, Department of General Medicine, Sri Guru Ram Das Institute of Medical Sciences and Research, Amritsar.

\section{NAME ADDRESS EMAIL ID OF THE} CORRESPONDING AUTHOR:

Dr. Preeti Singh Dhoat, \#41, 42 Krishan Nagar,

Lawrence Road, Amritsar - 143001.

E-mail: graceful_jivs@yahoo.com

Date of Submission: 28/02/2014.

Date of Peer Review: 01/03/2014.

Date of Acceptance: 17/03/2014.

Date of Publishing: 04/04/2014. 